\title{
EXPLORATION UNDER REGOLITH COVER, AND THE PROBLEM OF REMANENT MAGNETISM: AN EXAMPLE FROM THE TANAMI AU PROVINCE
}

\author{
Kate Pfeiffer ${ }^{1}$, Nicholas G. Direen ${ }^{1}$ \& Mike Sexton ${ }^{2}$ \\ ${ }^{1}$ CRC LEME, School of Earth \& Environmental Sciences, University of Adelaide, SA 5005 \\ ${ }^{2}$ Newmont Australia Pty. Ltd., Adelaide, SA
}

\section{INTRODUCTION}

Newmont Australia and its predecessors (Normandy \& NFM) have been exploring for Au in the Tanami region for over twenty years. In the process they have acquired many thousands of line kilometres of airborne magnetic surveys. These datasets are the principal exploration tool for targeting new prospects within this area, which is covered by aeolian and fluvial regolith with thickness ranging from 0 to around $100 \mathrm{~m}$. A problem in interpreting aeromagnetic images constructed from these data is the presence of magnetic anomalies, due to remanence, rather than simple induction. In these cases, drillholes targeted on the magnetic anomalies may miss the intended target due to the more complex magnetic field around the source. We have been investigating this phenomenon in The Granites and Dead Bullock Soak areas of the Tanami (Figure 1) with a view to understanding its causes.

Aeromagnetic data in this area was flown during June/July 2001 using a fixed winged aircraft. There are obvious highly magnetised beds, but unusual high amplitude linear magnetic lows to the north of some magnetic highs are probably due to remanence. The sources of these negative anomalies have not previously been investigated, although they have been drilled during mineral exploration.

An assumption made when interpreting aeromagnetic surveys, is that the mineral creating induced magnetic anomalies is magnetite (Shive et al. 1992). Most of the time, this assumption holds but it is important, especially when there are unusual negative anomalies, to determine the mineralogical source of the magnetic signature. Monoclinic pyrrhotite is normally a ferromagnetic mineral (Clark 1997), but can also hold quite a strong

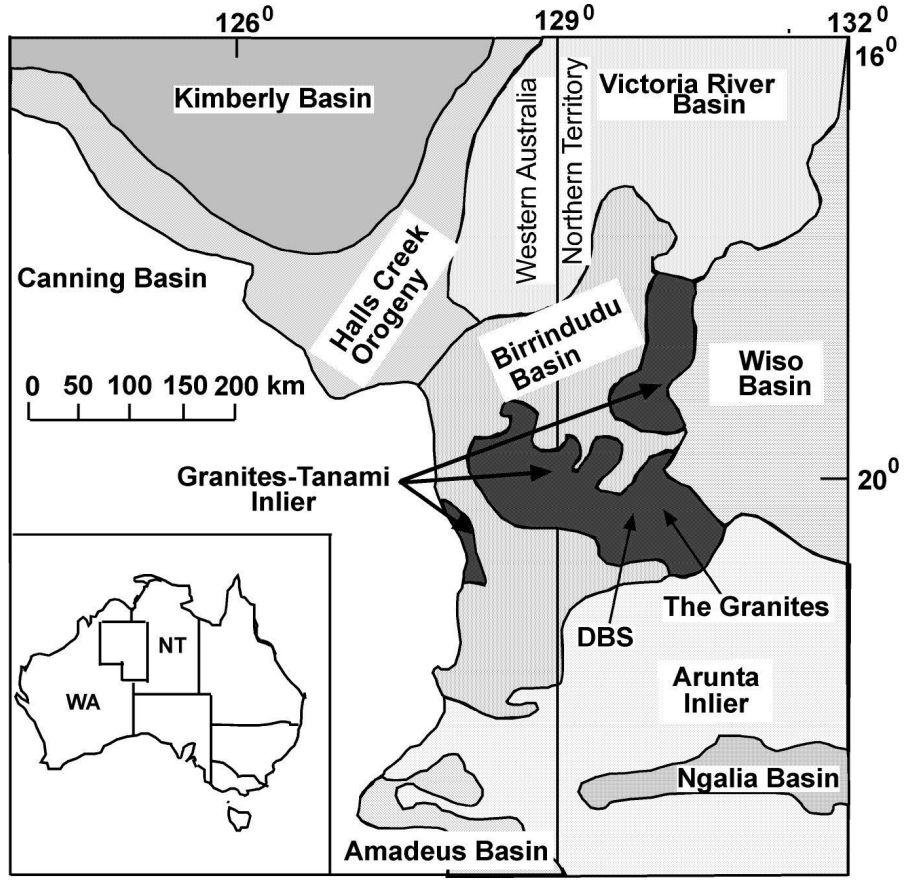

Figure 1: Geographical location of The Granites and Dead Bullock Soak regions, NT, modified from Adams (1997). remanent magnetism (Henkel 1994). Large concentrations (several wt. \%) of ferrimagnetic, monoclinic pyrrhotite in a rock is one possible source of spurious negative anomalies in aeromagnetic datasets. Others include titanohematites and single domain magnetite (Clark 1997). We have undertaken petrological, chemical and petrophysical analysis to determine the source of these anomalies in the Tanami.

\section{METHODS \& RESULTS}

Extensive mineral exploration drilling programs throughout area of The Granites/Dead Bullock Soak have intersected rocks spatially associated with high amplitude negative magnetic anomalies. Holes sampled in our study were chosen for both high concentrations of magnetite and pyrrhotite, as recorded in company drill logs, but also their spread of geographical locations throughout the Tanami area. Each drill hole was measured for magnetic susceptibility, and had between three and eight samples taken for petrological, chemical and remanence analysis.

Magnetic susceptibility measurements were made using a Fugro GMS-2 magnetic susceptibility meter. These readings were made over a $30 \mathrm{~cm}$ interval enveloping core intervals where a high proportion of magnetic 
minerals (magnetite and pyrrhotite) had been recorded in company drill logs.

Optical petrology was undertaken on 38 samples from these intervals; magnetite and pyrrhotite dominate the opaque mineral assemblage, with only trace amounts of pyrite, chalcopyrite and arsenopyrite. Magnetite shows different crystal forms, as shown in Figure 2. Type I magnetites are medium-fine grained euhedral and subhedral grains, that contain no matrix inclusions (Figure 2a). Type II magnetites are retrogressed relict grains with pseudomorphed euhedral shapes (Figure 2b), and contain recrystallised inclusions. Type III magnetites are very fine grains dispersed through the matrix.

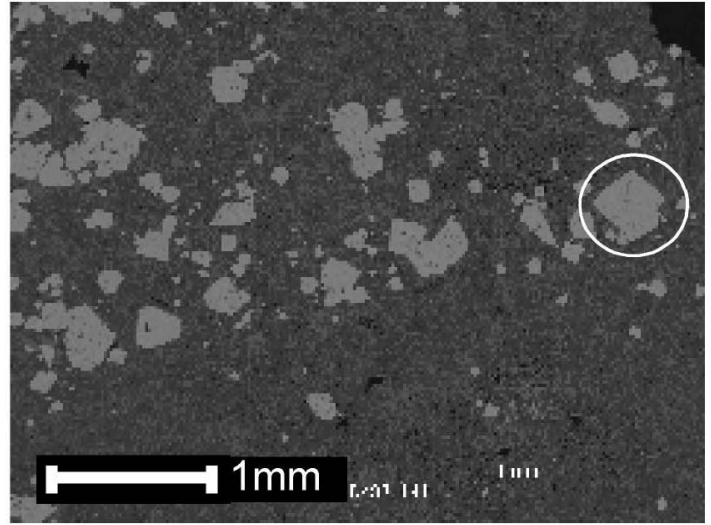

Figure $2 a$

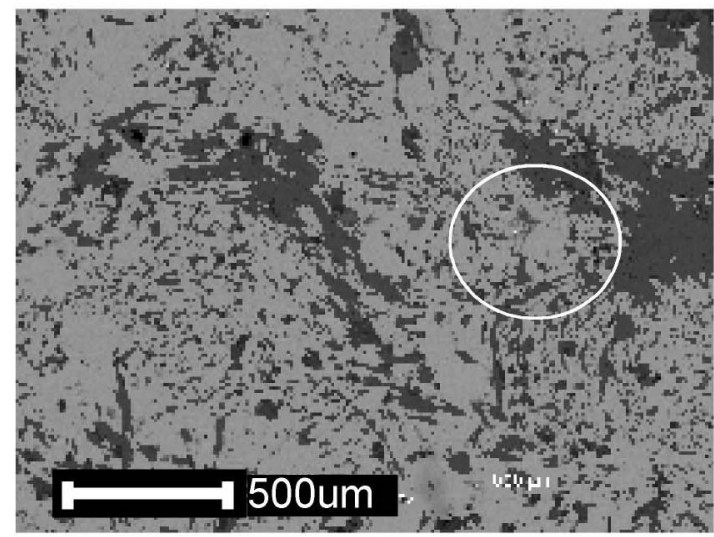

Figure 2c

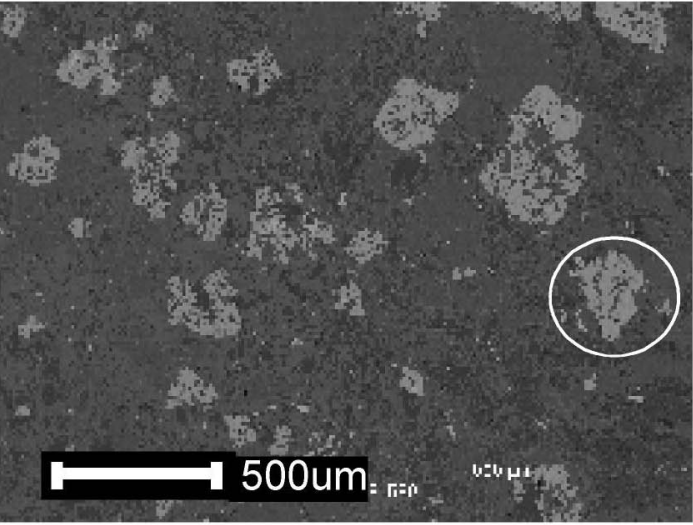

Figure $2 b$

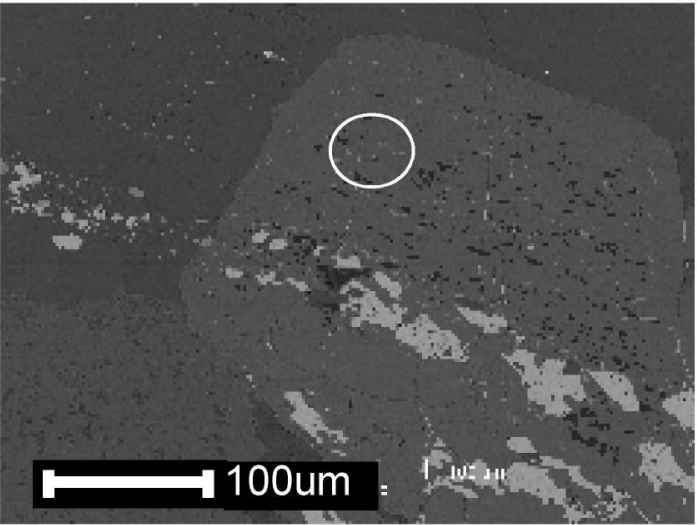

Figure 2d

Figure 2: SEM images of the main opaque minerals observed in the Tanami samples: a. type I magnetite; $\mathbf{b}$. type II magnetite; c. pyrrhotite; and, $\mathbf{d}$. very fine grained ilmenite.

Pyrrhotite forms subhedral grains in discrete veins; fine and very fine-grained pyrrhotite is also present as diffuse selvages to these veins (Figure 2c). Ilmenite is present in most sections as very fine grains in no particular orientation (Figure 2d), and is found in the presence of both magnetite (as described by Williams 2002) and pyrrhotite.

After optical analysis some thin-sections were selected for further investigation of their chemical compositions. This work analysis was completed on the CAMECA SX51 Electron Microprobe housed at Adelaide Microscopy. Types I and II magnetites are composed primarily of $\mathrm{Fe}(\mathrm{II}) \mathrm{Fe}_{2}(\mathrm{III}) \mathrm{O}_{4}$, but $\mathrm{Ca}$ and $\mathrm{Si}$ are often major contributors with $\mathrm{Al}, \mathrm{Mg}$ and Ti having a minor contribution. Radzik (1998) and Williams (2002) also investigated this relatively pure magnetite, obtaining similar results. Ilmenite grains have Fe $>>$ Mn, but there is little subsititution of other elements.

Natural remanent magnetic analysis was carried out at CSIRO (North Ryde) using a 2G Enterprises model 2G600 automatic AF system with a sensitivity better than $0.1 \times 10^{-5} \mathrm{~A} / \mathrm{m}$. Each specimen was cut into a cylinder up to $2.54 \mathrm{~cm}$ in diameter. The instrument used was a fluxgate spinner, where specimens are exposed to an alternating sinusoidal magnetic field that decays with time (Butler 1998). 
The Koenigsberger ratio (Q) (the ratio of the induced magnetisation to the remanent magnetisation) was obtained for each sample (McEnroe et al. 2001). This ratio tests a sample's capability to sustain a stable remanent magnetism. The inclination and declination of the main remanent vector for each sample was found along with the magnetic susceptibility and intensity.

Six samples were also analysed to determine their Curie temperatures, using a stepwise thermal demagnetisation process. These samples were chosen to evaluate the magnetic minerals contributing to the different populations of Koenigsberger ratios (Q) within the sample set. Samples with high $Q(Q>10)$ were found to be dominated by remanently magnetised pyrrhotite (Figure 3a), with thermal alteration resulting in the creation of magnetite at higher temperatures $\left(570^{\circ} \mathrm{C}\right)$. Upon cooling, due to magnetite creation, the thermomagnetic curve is at a higher magnetisation than that of its heating counterpart. Samples with low $Q(Q<1)$ were dominated by ferromagnetic magnetite (Figure $3 b$ ). The obvious slope down to zero magnetisation

at around $580^{\circ} \mathrm{C}$ is indicative of the Curie temperature of magnetite; the reversible thermomagnetic curve indicates the magnetite is likely to be multidomain. Two samples with intermediate ratios $(1<\mathrm{Q}<10)$ are quite different. A sample with $\mathrm{Q}=1.6$ has a curve indicative of multidomain magnetite; the other sample, with $\mathrm{Q}=6.5$, displays a large difference between the heating and cooling curves, and an irreversible heating-cooling pattern. This result is similar to samples with high $\mathrm{Q}$ values, where magnetite has been created by thermal breakdown of pyrrhotite. In the case of the sample with $\mathrm{Q}=$ 6.5 , the magnetite produced upon heating of pyrrhotite may not be pure.
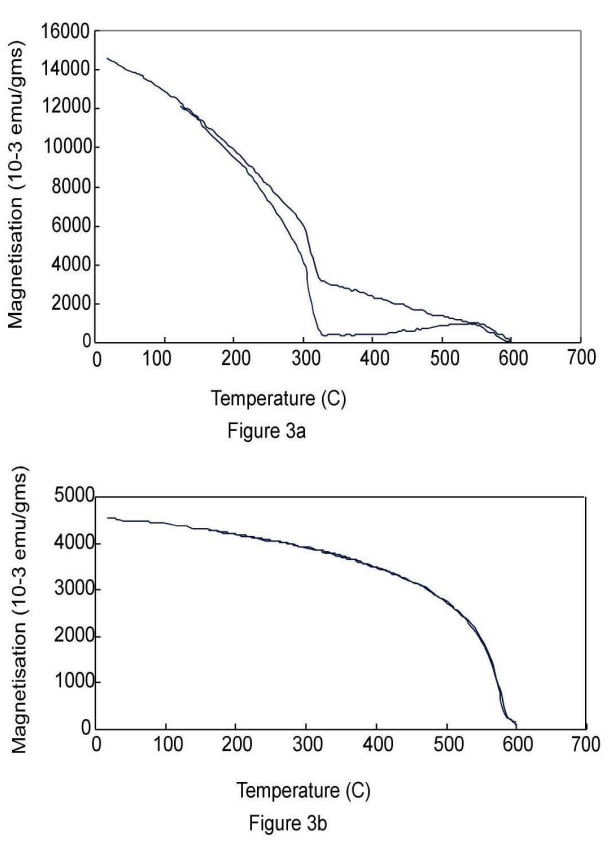

Figure 3: When magnetisation is plotted against temperature the main magnetic mineral is indicated. Figure 3a demonstrates the thermal demagnetisation of pyrrhotite whereas Figure $\mathbf{3 b}$, with the thermal demagnetisation decreasing rapidly at $570^{\circ} \mathrm{C}$, indicates magnetite.

\section{CONCLUSIONS AND IMPLICATIONS}

There is strong remanent magnetism in the vicinity of both The Granites and Dead Bullock Soak mines in the Tanami Au province. From petrological, chemical, alternating field and Curie temperature analyses, we have determined that the high remanence and low magnetic susceptibility is a result of bands of monoclinic pyrrhotite. Very fine-grained metamorphic ilmenite is also associated with the high remanent magnetism, but is shown not to be contributing to the remanence, on the basis of Curie temperature analysis. Euhedral and subeuhedral magnetites are porphyroblastic metamorphic mineral growths, some with evidence of retrogression. In both types, stoichiometry indicates they are pure magnetite, with no evidence of mobile Ti (Williams 2002) entering the magnetite structure. Rocks with high concentrations of magnetite display lower remanent magnetism but a high magnetic susceptibility (Figure 4), and would produce magnetic anomalies due to induction alone. Pyrrhotite is thus very important when using magnetic signatures to map beneath regolith in the Tanami region. It does not contribute to the high amplitude magnetic signatures, instead creating high amplitude negative anomalies, due to its ability to hold remanent magnetism.

A further important property of the pyrrhotite in the Tanami is its occurrence in the paragenetic sequence associated with Au-bearing sulphides (pyrrhotite and arsenopyrite). This process is still under investigation, but it is hoped that the

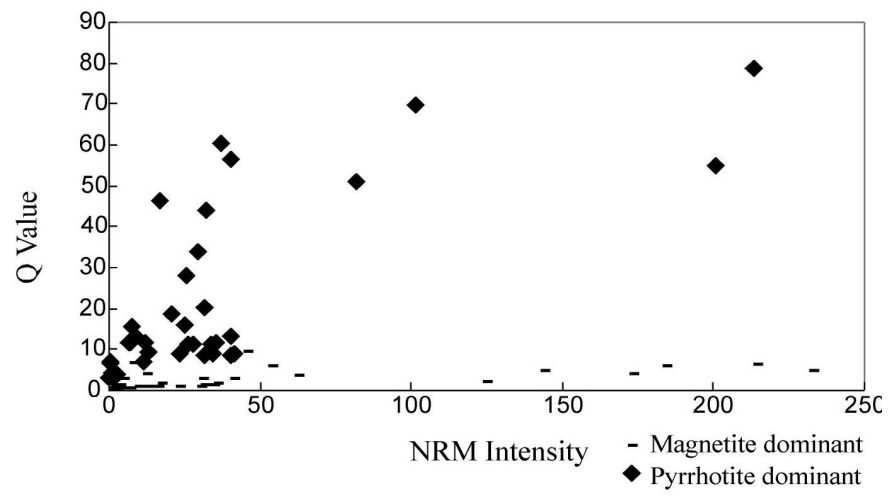

Figure 4: Plotting the Koenisberger (Q) ratio against the natural remanent magnetism (NRM) intensity indicates there are discrete differences between the samples that have higher concentrations of pyrrhotite or magnetite. 
remanent magnetic anomalies may be an important indicator of the operation of the hydrothermal Au mineral system within specific rock volumes beneath the transported regolith cover.

Acknowledgements: Newmont Australia and CRC LEME provided project funding. Phil Schmidt (CSIRO, North Ryde) conducted magnetic analyses.

\section{REFERENCES}

ADAMS G. 1997. Structural evolution and ore genesis of The Granites gold deposits, Northern Territory. $\mathrm{PhD}$ thesis, University of Adelaide, unpublished.

Butler R.F. 1998. Paleomagnetism: Magnetic Domains to Geologic Terranes. Department of Geosciences University of Arizona Tucson, Arizona, pp 105-107.

ClARK D.A. 1997. Magnetic petrophysics and magnetic petrology: aids to geological interpretation of magnetic surveys. AGSO Journal of Australian Geology and Geophysics 17, 83-103.

HENKEL H. 1994. Standard diagrams of magnetic properties and density - a tool for understanding magnetic petrology. Journal of Applied Geophysics 32, 43-53.

McEnroe S.A., Robinson P. \& PANish P.T. 2001. Aeromagnetic anomalies, magnetic petrology, and rock magnetism of hemo-ilmenite- and magnetite-rich cumulate rocks from the Sokndal Region, South Rogaland, Norway. American Mineralogist 86, 1447-1468.

RADZIK N.A. 1998. The relationship between magnetite occurrence and gold mineralisation in the Callie gold deposit, Tanami Region, Northern Territory, Australia. Honours thesis, University of Adelaide, unpublished.

Shive P.N., Blakely R.J., Frost B.R. \& Fountain D.M. 1992. Magnetic properties in the lower continental crust. In: Fountain D.M., ARCulus R. \& KAY R.W. eds. Continental Lower Crust. Elsevier, Amsterdam, New York, pp. 145-170

WiLliams N.C. 2002. Controls on mineralisation at the Callie lode gold deposit, Tanami Desert, Northern Territory. Minerals and Geohazards Division, Geoscience Australia, Canberra, Geoscience Australia Professional Opinion 2002/09. 